\title{
Insights from animal models on the immunogenetics of leprosy - A Review
}

\author{
Linda B Adams ${ }^{1 /}$, Maria T Pena ${ }^{1,2}$, Rahul Sharma ${ }^{1,2}$, \\ Deanna A Hagge ${ }^{3}$, Erwin Schurr', Richard W Truman'

\begin{abstract}
'Department of Health and Human Services, Health Resources and Services Administration, Bureau of Primary Health Care, National Hansen's Disease Programs 2Pathobiological Sciences, Louisiana State University, School of Veterinary Medicine, Baton Rouge, LA, USA ${ }^{3}$ Anandaban Hospital, Kathmandu, Nepal ${ }^{4}$ McGill Centre for the Study of Host Resistance, The Research Institute of the McGill University Health Centre, Montreal, Quebec, Canada
\end{abstract}

A variety of host immunogenetic factors appear to influence both an individual's susceptibility to infection with Mycobacterium leprae and the pathologic course of the disease. Animal models can contribute to a better understanding of the role of immunogenetics in leprosy through comparative studies helping to confirm the significance of various identified traits and in deciphering the underlying mechanisms that may be involved in expression of different disease related phenotypes. Genetically engineered mice, with specific immune or biochemical pathway defects, are particularly useful for investigating granuloma formation and resistance to infection and are shedding new light on borderline areas of the leprosy spectrum which are clinically unstable and have a tendency toward immunological complications. Though armadillos are less developed in this regard, these animals are the only other natural hosts of M. leprae and they present a unique opportunity for comparative study of genetic markers and mechanisms associable with disease susceptibility or resistance, especially the neurological aspects of leprosy. In this paper, we review the recent contributions of genetically engineered mice and armadillos toward our understanding of the immunogenetics of leprosy.

Key words: experimental animal models - knockout mice - armadillos - IL-12 - PARK2 - Toll-like receptor

Mycobacterium leprae is among the most monomorphic of bacterial pathogens and shows little genomic sequence diversity between isolates from different continents, ethnic groups or host species (Truman et al. 2011). There are no known pathological variants of M. leprae, yet leprosy is manifest over a broad clinical and histopathological spectrum with widely divergent immunological features. Typically a rare disease in populations, only a small proportion of humans appear to be susceptible to the infection. Though environmental exposures may have some modulating influence on an individual's response to $M$. leprae, the spectrum of host responses and general susceptibility to leprosy appear to be innate or genetically derived.

Most genetic studies addressing issues of susceptibility to leprosy or the immunological pathways involved in pathogenesis of the infection have been conducted in human populations. This is in part due to an appropriate focus on the relevant host species; but it also is a matter of the general paucity of animal models for leprosy and the few laboratories around the world that are equipped to deal with $M$. leprae-infected animals. However, animal models can contribute to our understanding about immunogenetics in leprosy, especially

Financial support: NIH NIAID (RO1-AI050027, IAA-2646), HRSA, CIHR (MOP-15662)

+Corresponding author: ladams@hrsa.gov

Received 17 January 2012

Accepted 5 June 2012 through comparative studies to confirm the relative importance of specific genetic markers and in deciphering the underlying mechanisms involved in the expression of different disease phenotypes.

Even early leprosy investigators noted differing growth potentials for M. leprae according to the genetic background of the mouse strains being used in their foot pad studies (Reisner 1943, Shepard 1962, Pattyn 1965). Variations in susceptibility to mycobacterial infection among mice have been recognized for more than 60 years and investigation of the differential susceptibility of mouse strains to infection with Mycobacterium bovis (BCG) led to discovery of a single autosomal gene (Bcg/Nrampl/Slcllal) that determines susceptibility to M. bovis, Mycobacterium lepraemurium and a variety of atypical mycobacteria (Gros et al. 1981, Schurr et al. 1990). Today, a wide variety of genetically engineered "knockout" mouse strains are available and directed mutagenesis can be used to create a large number of specific genetic defects. Engineered mice are now being used to dissect the immune response pathways that influence granuloma formation during infection with M. leprae and to address specific issues with regards to disease susceptibility. In addition, armadillos are now recognized as natural hosts of $M$. leprae and recent completion of their whole genomic sequence now makes it possible to explore their genetic background and specific physiological responses to M. leprae infection.

The course of $M$. leprae-infection in animals is much shorter than in humans. Experimental studies in animal hosts with well defined genetic backgrounds can bring unique insights into the immunogenetic factors that might influence leprosy in humans. In this paper we 
summarize data evolving from the use of genetically engineered mouse strains and nine-banded armadillos with regard to factors affecting overall susceptibility to infection with M. leprae and the pathogenesis of leprosy.

Ethics - Experiments were approved by the Institutional Animal Care and Use Committee and performed in compliance with all applicable state and federal laws and regulations in accordance with Policy on Humane Care and Use of Laboratory Animals. The National Hansen's Disease Program's Assurance of Compliance (\#A3032-01) is registered with the Office of Laboratory Animal Welfare.

Mouse strains used to study immunogenetics of leprosy - Conventional (immunocompetent) mice - Charles Shepard (1960) demonstrated the multiplication of M. leprae in the foot pads of mice in the early 1960's. Based on the knowledge of the preference of M. leprae for the cooler areas of the body, this was the first time the bacilli had been successfully and reproducibly cultured outside the human host. In this model of infection, an inoculation of a few thousand bacilli into the foot pads of immunocompetent mice results in growth which plateaus at approximately one million organisms. The histopathological changes consist of small granulomas containing infected macrophages and lymphocytes and there is essentially no dissemination of infection. Thus, immunocompetent mice are by and large resistant to disease development with M. leprae. Although growth was limited, this ability to "culture" $M$. leprae was a breakthrough which launched numerous studies (reviewed in Levy \& Ji 2006), including the isolation and propagation of bacilli from human lesions, evaluation of new leprosy therapeutics and development of assays for the detection of drug resistant strains of $M$. leprae and diagnostics. In addition, it allowed for fundamental investigations of host resistance and vaccine evaluation.

Athymic nu/nu and other immunecompromised mice - Soon after the development of this standard "mouse foot pad assay," various investigators applied this technique to immunodeficient murine strains, in part, with the aim of developing models more representative of human lepromatous leprosy (LL). Studies in neonatally thymectomized or congenitally athymic mice and rats (Rees 1966, Colston \& Hilson 1976, Dawson et al. 1983, Chehl et al. 1983), T900r mice (Ebenezer et al. 2002), as well as later studies in SCID mice (Yogi et al. 1991, Azouaou et al. 1993), established the significance of lymphocytes, especially $\mathrm{T}$ cells, in host defence in leprosy. In athymic nu/nu mice, multiplication of $M$. leprae in the foot pad can reach $1 \times 10^{10}$ or more bacilli with the infected tissue composed primarily of macrophages heavily laden with the bacilli (Hagge et al. 2004). In this regard, athymic nu/nu mice show characteristics of LL disease. In addition to their immunological significance, athymic nu/nu mice are utilized for routine culture of large numbers of highly viable $M$. leprae for experimental use (Truman \& Krahenbuhl 2001).

Gene knockout mice - The development of genetically engineered mice has opened the possibility for addition- al murine models for the study of leprosy. Using mice with deficiencies at specific points in the cascade of the immune response provides more options for analyzing the effects of infection compared to the essentially allor-nothing approach afforded by immunocompetent and athymic nu/nu mice. This is especially promising in the search for models for the borderline areas of the spectrum which are clinically unstable and have a tendency toward immunological complications that are poorly defined (Scollard et al. 2006a). One must acknowledge, however, that leprosy is a complex disease. Entry into the spectrum and progression of the disease is likely influenced by an amalgamation of several personal (e.g., age, hormones) and environmental (e.g., poor nutrition, co-infections with immunemodulating parasites, viruses, or worms, or exposure to other mycobacteria) pressures, as well as genetic factors which can affect long term immune status. It is, therefore, unlikely that a single gene determines the outcome of infection across varied endemic populations and environments. However, studying infection in the context of defined immune deficiencies can lend insights into both the causal and resultant aspects of exposure and may suggest targets for prevention, early diagnosis and improved treatments.

In our gene knockout mouse studies, we have utilized the Shepard model and a higher dose lepromin test-like model (Adams et al. 2000, 2002, Cooper et al. 2002a, Hagge et al. 2007, 2009). The Shepard model is used for bacterial growth and enumeration and molecular and histological evaluation. As a complement, the high dose model is used to determine the ability of the host to form a granuloma in response to M. leprae infection. It employs a sufficient initial inoculum to stimulate a relatively rapid and larger cellular infiltrate. Foot pad induration can be easily measured over time as an external indicator of cellular infiltration. Moreover, foot pad granuloma cells can be harvested at various times post-infection for sophisticated exploration of their composition and function by flow cytometry and molecular analyses. Clinical correlates for these types of granuloma investigations have been attempted (Moura et al. 2007), but can be difficult at endemic field sites as access to the requisite technology and fresh skin biopsies from leprosy patients rarely co-exist.

In addition, using the higher dose infection model has enabled us to examine the granuloma as opposed to relying on the lymph nodes for discerning immunoreactivity. Since lymph node cells are typically easy to obtain and of sufficient number for advanced methods of analyses, they have been studied in place of the granuloma population and regarded as representative of the immuneprotective response. In our studies, however, we found a striking difference in the cellular composition at the site of infection itself and the popliteal lymph nodes draining this site (Hagge et al. 2007, 2009). While the lymph nodes of $M$. leprae-infected immunocompetent mice are composed of $\mathrm{B}$ cells and naïve $\mathrm{CD} 4^{+} \mathrm{T}$ cells, the lymphocytes which infiltrate the foot pads are primarily $\mathrm{CD}^{+}$effector T cells, presumably there due to a selective immigration or retention of these cells in the granuloma (Table I). Thus, it is important to emphasize the 
significance of these relevant cells. In leprosy, the host response to $M$. leprae centres around the establishment, composition, configuration and actions of the granuloma and these characteristics are distinctive depending on the patient's position in the clinical/immunepathological spectrum. It is in this microenvironment that immunity to $M$. leprae is carried out and results from the intricate interaction of the various host cells and their products with the organism and its constituents.

It has long been speculated that there may be a genetic predisposition(s) for contracting leprosy upon exposure to $M$. leprae. Polymorphisms in several genes in both the innate and adaptive phases of the immune response have been associated with susceptibility to intracellular infections (reviewed in van de Vosse et al. 2009, Alter et al. 2011, Cardoso et al. 2011b). Below is an overview of the outcomes of $M$. leprae infection in mice with a knockout in some of the genes associated with leprosy.

Interleukin (IL)-12/IL-23/interferon (IFN) $\gamma$ axis Deficiencies in the IL-12/IL-23/IFN $\gamma$ axis are associated with mendelian susceptibility to mycobacterial diseases (MSMD), a group of inherited genetic mutations resulting in the impaired development along the $\mathrm{T}$ helper (Th) 1 cytokine pathway (van de Vosse et al. 2009, Cottle 2011). MSMD results in a severe impairment of the protective host response and a high susceptibility primarily to poorly pathogenic environmental mycobacterial and $M$. bovis BCG associated vaccines. Mutations have been identified in the IL-12p40 subunit, IL-12R $\beta 1$ chain, the IFN- $\gamma \mathrm{R} 1$ and IFN- $\gamma \mathrm{R} 2$ chains, tyrosine kinase 2 and nuclear factor- $\kappa \mathrm{B}(\mathrm{NF}-\kappa \mathrm{B})$-essential modulator. Mutations can be recessive or dominant and result in partial or complete gene deficiency. Importantly, recent studies have linked rare amino acid changes in IL-12R $\beta 1$ to childhood tuberculosis (Boisson-Dupuis et al. 2011).

IL-12/IL-23 knockout mice - IL-12 and IL-23 are key regulatory cytokines in innate and adaptive immunity. IL-12, produced early in infection by macrophages and monocytes, promotes the development of a Th1 type cell mediated immune response which is crucial for antimicrobial immunity to intracellular pathogens. IL-23 is produced primarily by macrophages and dendritic cells; however, instead of inducing the differentiation of naïve T cells into IFN $\gamma$ generating Th1 cells, IL-23 induces an alternative $\mathrm{T}$ cell subset, Th17 cells, which produce the proinflammatory cytokine, IL-17. This response is important for the induction of chronic inflammation and granuloma formation (reviewed in Khader \& Gopal 2010, Torrado \& Cooper 2010). Both IL-12 and IL-23 share a common p40 subunit and p40/- mice have a reduced ability to control growth of $M$. tuberculosis (Cooper et al. 2002b, Khader et al. 2005).

To evaluate the roles of IL-12 and IL-23 in experimental leprosy, we studied $M$. leprae infection in $\mathrm{p} 40^{-/-}$mice. As shown in Fig. 1A, growth of $M$. leprae was significantly enhanced in $\mathrm{p} 40^{-/-}$mice $(\mathrm{p}<0.01)$. Histopathologically, $\mathrm{C} 57 \mathrm{BL} / 6 \mathrm{~J}$ foot pads exhibited mild lymphocytic and histiocytic infiltrates; $\mathrm{p} 40^{-/-}$mice also developed only a mild inflammation. In the high dose model, foot pad induration was markedly decreased compared to that of C57BL/6J mice (Fig. 1B). Leukocyte accumulation into both control and $\mathrm{p} 40^{-/-}$foot pads consisted primarily of $\alpha \beta^{+} \mathrm{CD} 4^{+} \mathrm{T}$ cells and $\mathrm{CD} 11 \mathrm{~b}^{+}$macrophages; however, the $\% \mathrm{CD}^{+}$cell infiltration was augmented in $\mathrm{p} 40^{-/-}$mice. Furthermore, CD69 and CD25 expression were markedly augmented in the $\mathrm{p} 40^{-/-}$foot pads, especially on the $\mathrm{CD} 8^{+} \mathrm{T}$ cell population. Expression of IFN $\gamma$ and tumour necrosis factor (TNF), cytokines crucial to an effective Th1 response and CXCL-10, CCL3 and CCL4, chemokines important in granuloma formation, were significantly lower in $\mathrm{p} 40^{-/-}$ foot pads compared to $\mathrm{C} 57 \mathrm{BL} / 6 \mathrm{~J}$ foot pads as infection progressed (Fig. 1C). These results indicate that, compared to $\mathrm{C} 57 \mathrm{BL} / 6 \mathrm{~J}$ mice, $\mathrm{p} 40^{-/}$mice exhibited a decreased ability to control $M$. leprae growth and evidenced reduced foot pad induration with altered $\mathrm{T}$ cell composition and cytokine/chemokine production due to the lack of protective IL-12 and proinflammatory IL-23, respectively.

IFN $\gamma$ knockout mice - A key role for $\mathrm{CD}^{+}$and $\mathrm{CD}^{+} \mathrm{T}$ cells in immunity to mycobacterial infections is the production of IFN $\gamma$, a cytokine important for antimycobacterial activity and for regulating IL-17-producing T cells (Cruz et al. 2006). In humans, an association between leprosy resistance and the single nucleotide polymorphism (SNP), $I F N G^{+} 874 \mathrm{~T}$, has been found (Cardoso et al. 2011b). To study the role of IFN $\gamma$ in experimental leprosy, control and IFN $\gamma^{-/-}$mice were infected in the foot pads as per the Shepard model (Adams et al. 2002). Initially, the rate of growth of $M$. leprae was similar in both strains of mice, but growth continued and plateaued at approximately one log higher in IFN $\gamma^{-/}$mice. By nine months

TABLE I

Cellular composition of the foot pads and lymph nodes of Mycobacterium leprae-infected mice

\begin{tabular}{lcc}
\hline Marker & Foot pad & Lymph node \\
\hline Leukocytes & Macrophages $>$ lymphocytes & Lymphocytes $>$ macrophages \\
Lymphocytes & T cells $>$ B cells & B cells $>$ T cells \\
T cells & $\mathrm{CD} 4^{+}>\mathrm{CD} 8^{+}$ & $\mathrm{CD} 4^{+}=\mathrm{CD} 8^{+}$ \\
$\mathrm{CD} 4^{+}$ & Effector $>$naïve & Naïve $>$effector \\
$\mathrm{CD} 8^{+}$ & Effector $>$naïve & Naïve $>$effector \\
Macrophages & $\mathrm{I}^{-} \mathrm{A}^{+}>\mathrm{I}^{-} \mathrm{A}^{-}$ & $\mathrm{I}^{-} \mathrm{A}^{-}>\mathrm{I}^{-} \mathrm{A}^{+}$ \\
\hline
\end{tabular}


post-infection, the foot pads of the $M$. leprae-infected IFN $\gamma^{-/}$mice were visibly enlarged, indicating that cellular infiltration and granulomatous response continued to develop even after $M$. leprae growth was restrained. In contrast to control mice, IFN $\gamma^{-/}$mice exhibited large aggregates of mononuclear cells, were not organized into well-formed granulomas and contained only small collections of randomly interspersed lymphocytes, all features of borderline lepromatous lesions. Moreover, while few Ly6 $\mathrm{G}^{+}$polymorphonuclear (PMN) cells are ever found in the foot pads of control mice, there were substantial increases in both the number and percentage of PMNs in the IFN $\gamma^{-/}$foot pads. Of interest, this regulation of PMN infiltration into leprosy granulomas by IFN $\gamma$ may be of use in the study of leprosy reactions.

LT- $\alpha$ knockout mice - Using whole genome based genetic approaches (positional cloning), Alcais et al. (2007) identified a polymorphism, $L T A^{+} 80$ located in the promoter region of the lymphotoxin- $\alpha(\mathrm{LT} \alpha)$ gene, that was significantly associated with an increase in leprosy per $s e$. This association was found in three distinct populations of patients (i.e. Vietnamese, Indian and Brazilian) and was strongest in patients first diagnosed when less than 16 years old. Immunologically, LT $\alpha$ has been im-
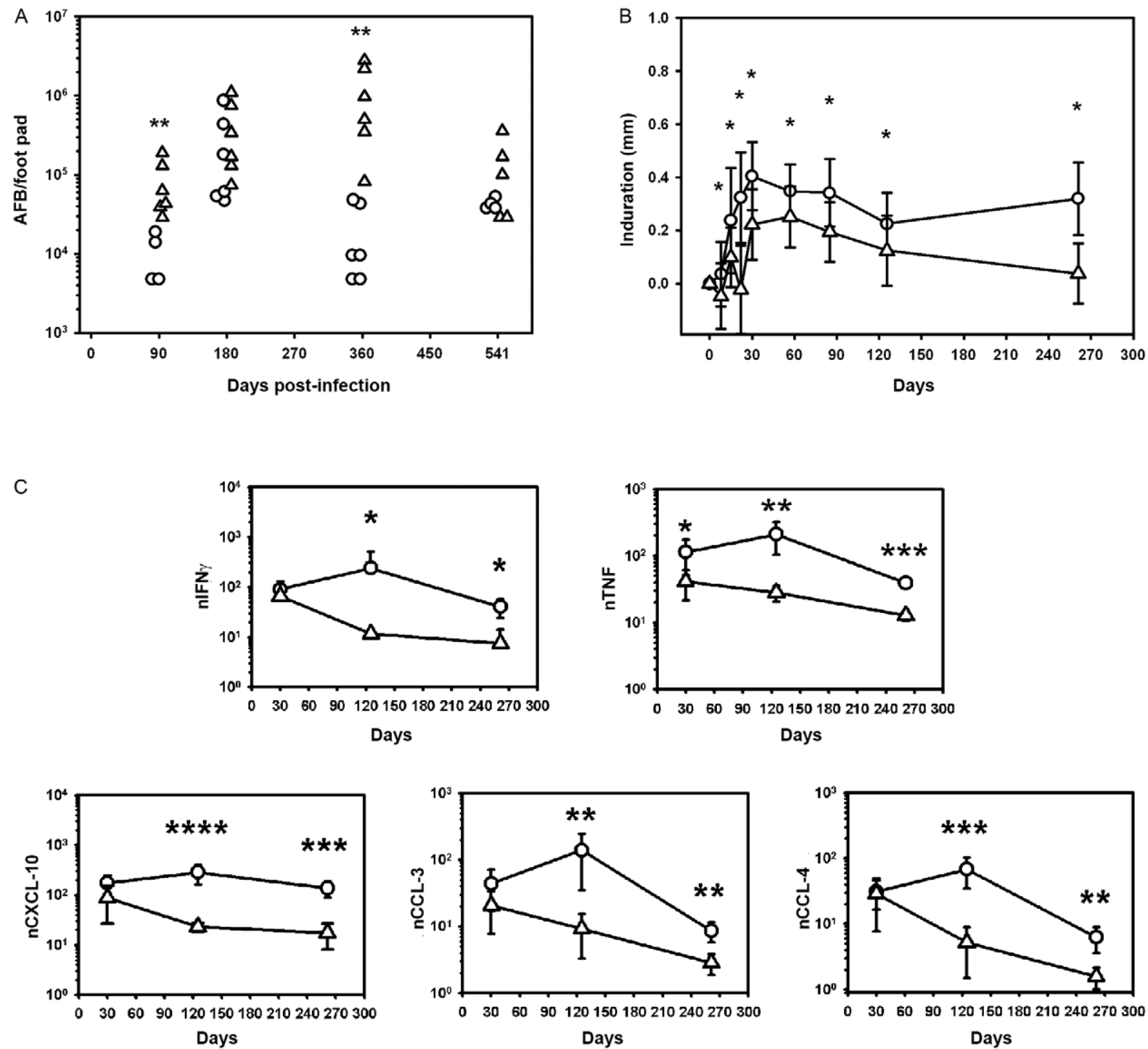

Fig. 1: Mycobacterium leprae infection in $\mathrm{p} 40^{-/}$mice. A: C57BL/6J (circles) and $\mathrm{p} 40^{-/}$(triangles) mice were infected in each hind foot pad with $6 \times 10^{3}$ viable $M$. leprae (Shepard growth model). At 90, 180, 360 and 540 days post-infection, the number of acid fast bacilli (AFB) per foot pad was determined. Each symbol represents one mouse. The threshold of counting ability is $4.8 \times 10^{3} \mathrm{AFB}$ per foot pad; B: C57BL/6J (circles) and $\mathrm{p} 40^{-/}$(triangles) mice were inoculated in each hind foot pad with $3 \times 10^{7}$ viable $M$. leprae (high dose granuloma model). Foot pad induration was measured using a Vernier caliper. Data shown is mean \pm standard deviation of four mice per group; C: foot pad tissue from mice in B was harvested at 30, 126 and 261 days post-infection and RNA was purified and subjected to real-time polymerase chain reaction for cytokines and chemokines. Gene expression is normalized (n) using GAPDH mRNA expression. Data shown are means \pm standard deviation; IFN: interferon; TNF: tumour necrosis factor; *: $\mathrm{p}<0.05 ; * *: \mathrm{p}<0.01 ; * * *: \mathrm{p}<0.001 ; * * * * \mathrm{p}<0.0001$. 
plicated in the development of cell mediated immunity, the induction of chronic inflammation, the development of secondary lymphoid organs, cytokine, chemokine and cell adhesion molecule expression and $\mathrm{T}$ cell activation and memory cell persistence (Kratz et al. 1996, Rennert et al. 1996, Roach et al. 2001, Ware 2005, Soroosh et al. 2011). While the actual role of LT $\alpha$ in host defense against leprosy has not been identified, its probable proinflammatory functions are supported by its detection in tuberculoid leprosy lesions and in type 1 reactions (Yamamura et al. 1991, Bleharski et al. 2003).

In our studies (Hagge et al. 2009), multiplication of M. leprae in the foot pads of control and LTa-deficient mice was similar early in infection. However, bacterial counts were significantly higher in the LT $\alpha$-deficient mice late in infection, indicating a continued viable state. Few lymphocytes accumulated in the foot pad tissue. In the foot pad induration model, induration developed more slowly in LT $\alpha$-deficient mice, compared to control mice, was not sustained and actually declined. Flow cytometric analyses demonstrated few lymphocytes in LTa-deficient foot pads, but the popliteal lymph nodes contained significantly more $\mathrm{T}$ cells compared to control mice, indicating an aberration in cell trafficking. LT $\alpha$-deficient foot pads also exhibited a significantly lower expression of inflammatory cytokines and chemokines. These data indicate that LTa influences the onset of adaptive immunity to $M$. leprae and is essential for the maintenance of the granulomatous response during the chronic stage of infection in the mouse model. These features may underlie the association of genetic variants in the LT $\alpha$ gene and human leprosy.

TNF knockout mice - TNF is an important mediator in both innate and adaptive immunity and plays a pivotal role in inflammatory phenomena that culminate in either pathogenesis or resistance in mycobacterial disease (Adams et al. 1995, Flynn et al. 1995, Bean et al. 1999, Kaneko et al. 1999, Lin et al. 2010). Recently, the association of SNP TNF-308A with protection against leprosy was confirmed (Cardoso et al. 2011a). There is impaired TNF production in TLR2-deficient mouse macrophages upon stimulation with $M$. leprae (Bochud et al. 2003). Perhaps the best indicator of the importance of TNF in host defence against leprosy was revealed during treatment of individuals with anti-TNF therapy for rheumatoid arthritis who subsequently manifested borderline leprosy (Scollard et al. 2006b); moreover, when the anti-TNF therapy was discontinued, the patients developed type 1 reactions.

We have evaluated the role of TNF in experimental leprosy using both $\mathrm{TNF}^{-/}$and TNFR1 ${ }^{-/}$mice (Hagge et al. 2009). Upon $M$. leprae infection, growth was augmented 10 -fold throughout the nine-12 month infection period compared to control mice, emphasizing the importance of TNF in protection in both the acute and chronic stages of infection. Histopathologically, TNF-and TNFR $1^{--}$mice developed an extensive and diffuse lymphocytic infiltration that consisted predominantly of $\mathrm{CD} 4^{+} \mathrm{T}$ cells. Foot pad induration was initially delayed in both knockout strains, but developed to near control levels by 28 days post-infection (DA Hagge et al., un- published observations). Flow cytometric analyses demonstrated that leukocyte accumulation in all strains consisted primarily of $\alpha \beta^{+} \mathrm{CD}^{+}$effector T cells and I- $\mathrm{Ab}^{+}$ macrophages; however, this response, as well as CD69 ${ }^{+}$ $\mathrm{T}$ cell infiltration, was augmented in the knockout mice. Expression of inflammatory cytokines and chemokines was elevated in $\mathrm{TNF}^{-/}$and TNFR1 $1^{-/}$foot pads compared to control mice. These data suggest that TNF is crucial for the development and maintenance of an organized and protective granuloma and for the temperance of the inflammatory response in experimental leprosy.

IL-10 knockout mice - IL-10 is generated by T cells and macrophages and is an inhibitor of proinflammatory cytokine production. IL-10/- mice experimentally infected with many intracellular pathogens succumb rapidly, not due to overwhelming growth of the organisms, but from a severe pathology associated with an intense production of inflammatory mediators. There is evidence that IL- $10^{-/-}$mice have increased resistance to mycobacterial infection, forming larger granulomas containing macrophages with enhanced antimicrobial activity (Jacobs et al. 2000) and IL-10 supplementation in vitro prolongs M. leprae survival in macrophages (Fukutomi et al. 2004). In human genetic studies, the $-819 \mathrm{~T}$ allele, located in the promoter region of the ILIO gene, is associated with leprosy susceptibility (Cardoso et al. 2011b).

Upon foot pad infection using the Shepard model, similar growth kinetics for M. leprae multiplication were observed in both control and IL-10 ${ }^{-/}$mice (unpublished observations). Histopathologically, IL-10 $10^{-/}$mice developed an increase in the numbers of lymphocytes, macrophages and especially epithelioid cells, compared to control mice. IL10-/ mice also yielded slight increases in both foot pad induration and in the numbers of cells isolated from the foot pad in the high dose model. Therefore, IL-10 deficiency has only a mild immunomodulatory effect on M. leprae infection in the already resistant mouse model. Studies examining IL-10 deficiency in conjunction with other cytokine knockouts are currently underway.

PARK2 knockout mice - Using a positional cloning approach, genetic variants in the shared promoter region of the PARK2 and PACRG genes have shown an association with susceptibility to leprosy (Mira et al. 2004). In this study, significant linkage of chromosomal region 6 q25 with leprosy was found. Systematic association scanning of the linkage peak interval detected an association of PARK2/PACRG promoter variants with leprosy on two diverse ethnic backgrounds (i.e. Vietnamese and Brazilian). PARK2 and PACRG are part of the cellular ubiquitination system. PARK2 encodes an E3 ligase, parkin and has been associated with early onset juvenile Parkinson's disease. Parkin plays a role in controlled proteolysis, modulation of the cellular anti-oxidants response and mitochondrial function and regulation of innate immunity (Alter et al. 2011). It also has an anti-apoptotic effect (Berger et al. 2009) and promotes autophagy. Thus, it may have a role in protection against intracellular pathogens by promoting bacterial killing while avoiding apoptosis (Deretic 2010). Little is known regarding the function of PACRG. 
In an attempt to understand the immunological implications of PARK2 and leprosy, we evaluated M. leprae infection in PARK2 knockout mice. Mice were infected in the foot pads with M. leprae and bacterial growth was monitored for up to 12 months. Multiplication of M. leprae in the PARK2 foot pads was similar to that of the wild type (WT) littermate controls throughout infection (Fig. 2A). Interestingly, M. leprae-infected PARK2 foot pads exhibited elevated expression of IFN $\gamma$, TNF, IL12p35 and IL12/23p40 at four months post-infection, just prior to the peak of $M$. leprae growth which is halted due to the onset of adaptive immunity (Fig. 2B). In the foot pad induration model, foot pad enlargement was greater in the knockout compared to the WT foot pads (Fig. 2C). However, when lymphocyte and myeloid cells in the foot pads and lymph nodes were assessed by flow cytometry, there was no difference in the proportion of cell populations between the PARK2 and WT foot pads with any marker studied (i.e. CD3, CD4, CD8, CD69, CD44 ${ }^{\text {hi }} C D 62^{\text {lo }}, \mathrm{CD}_{4} 4^{\text {hi }} C D 45 R^{\text {lo }}$, B220, NK1.1.1, Ly6G, CD11b, CD11c, IAb). Bone marrow derived macrophages from both strains of mice supported $M$. leprae viability when infected with the bacilli in vitro. While the results in the PARK2 knockout mice were not as dramatic as those seen in many of the cytokine knockout mice, the effects of PARK2 on leprosy susceptibility may be extremely subtle and overcome by the strong adaptive immune response generated in the otherwise immunocompetent mouse model.

The armadillo model for immunogenetics in leprosy - Armadillos are well developed as the "hosts-of-choice" for in vivo propagation of $M$. leprae. Their unique susceptibility to experimental infection and capacity to develop heavy burdens of $M$. leprae with extensive neurological involvement has been well documented (Job et al. 1991, 1992, Truman \& Sanchez 1993, Scollard et al. 1996, 2006a, Scollard \& Truman 1999). The animals are typically inoculated intravenously with $1 \times 10^{9}$ highly viable $M$. leprae prepared through serial passage in nude mouse foot pads (Truman \& Krahenbuhl 2001). However, like humans, armadillos are not uniformly susceptible to infection and the response of individual animals can be highly idiosyncratic (Job et al. 1982, 1985b). Susceptible animals begin to show signs of a disseminated disease within six-12 months of inoculation and the infection will reach harvestable levels in 18-24 months (Truman et al. 1986). However, a proportion of the animals that we inoculate reliably resist experimental infection. Early reports noted that only about $50 \%$ of the armadillos experimentally inoculated with $M$. leprae appeared to develop disseminated leprosy suitable for propagative purposes (Kirchheimer \& Sanchez 1981, Job et al. 1983). In our laboratory today, $89 \%$ of the animals classified as lepromatous through lepromin skin testing develop disseminated infections after experimental inoculation and over a five year period we found 30/271 animals inoculated to be resistant to M. leprae.

Histopathological spectrum in armadillos - The histopathological appearance of $M$. leprae lesions in armadillos is indistinguishable from those seen in humans (Job et al. 1982, 1983, 1985c). Armadillos are fully intact immunologically and their robust immune system allows them to survive quite well in the natural environment where they have close contact with many soil micro-organisms. Armadillos are not especially prone to infection with other mycobacteria and on exposure to M. leprae they exhibit the full spectrum of histopathological responses like that seen in humans. The type of leprosy that each animal might manifest can be classified according to the RidleyJopling scale (ranging from lepromatous to tuberculoid) using the Mitsuda response to lepromin (Job et al. 1982, 1983, 1985a). In a survey of 392 armadillos from leprosy enzootic and non-enzootic areas across the southern United States of America (USA), we found that 281 (71\%) were classifiable as LL while the remaining animals exhibited histopathological reactions typical of borderline lepromatous, borderline tuberculoid or tuberculoid tuberculoid leprosy lesions (Table II). Armadillos occupy a broad geographic range in USA (Taulman \& Robbins 1996). However, the type of leprosy that each animal might manifest seems to have no relationship to their differing environmental exposures and appears to be innate.

Genetically identical quadruplicates - Armadillos always give birth to genetically identical quadruplicates and a heritable component in the armadillo's response to M. leprae also can be seen among litter-mates (Storrs \& Williams 1968). As shown in Table III, seven/eight of the sibling sets that we experimentally infected with M. leprae showed similar susceptibility and manifested similar numbers of bacilli at the time of harvest or removal. Individual litters appeared to be either high or low responders with siblings yielding more than $1 \times 10^{9}$ M. leprae/gram of reticuloendothelial tissue or exhibiting non-productive infections with either low bacillary counts $\left(<1 \times 10^{9} \mathrm{M}\right.$. leprae/gram) or suffering complications from the experimentally induced infection requiring their early removal from the colony. Observations on human genetically identical twins with leprosy also suggest an innate predisposition for the infection and mirror the similarity in responses seen here among armadillo siblings (Alter et al. 2011).

Influence of polymorphisms in Toll-like receptor (TLR): an important key for activation of the innate immune system is interaction with TLR - These highly conserved type 1 trans membrane proteins (Akira \& Takeda 2004, Misch et al. 2010) are expressed on different immune cells and recognize various pathogen-associated molecular patterns. TLR interaction can initiate an inflammatory response that augments killing or containment of invading organisms (Iwasaki \& Medzhitov 2004) or activate signalling pathways that alter the expression of various chemokines and cytokines. Polymorphisms in TLR alleles have been linked to susceptibility or resistance to a large range of microbial infections (de Diego et al. 2007) and specific polymorphic loci on TLR-1, TLR-2 and TLR-4 have been linked with the host response to leprosy in humans (Misch et al. 2010).

Dimerization of TLR1 and TLR2 is required for recognition of many mycobacterial proteins and lipopeptides (Heldwein \& Fenton 2002, Berrington \& 
A
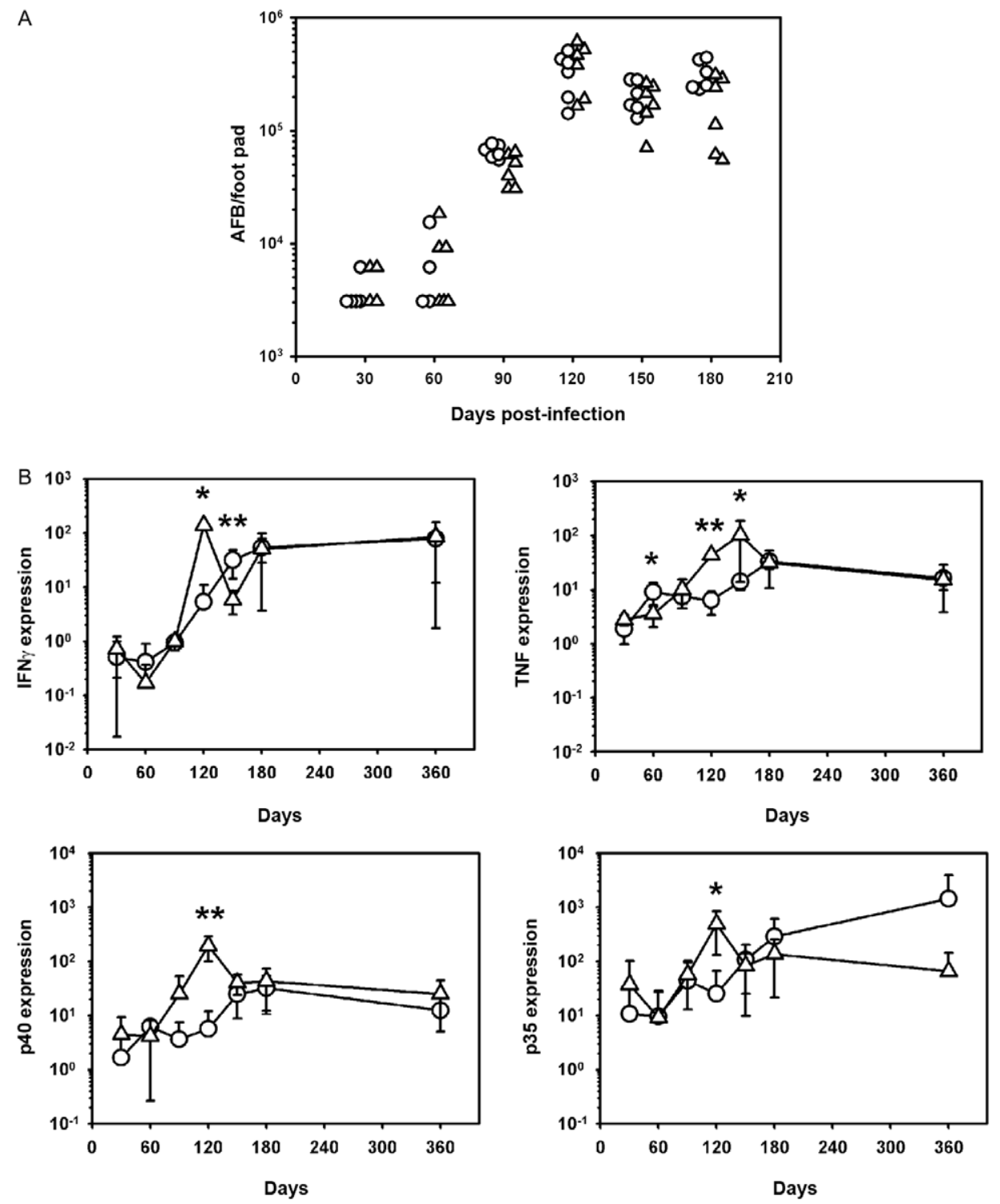

C

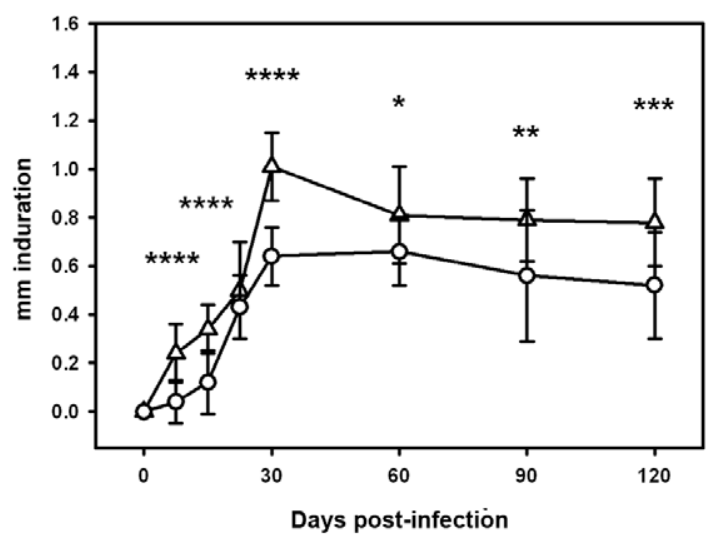

Fig. 2: Mycobacterium leprae infection in PARK2 ${ }^{-\digamma}$ mice. A: wild type (WT) (circles) and PARK2-/ (triangles) mice were infected in each hind foot pad with $6 \times 10^{3}$ viable M. leprae. At 30, 60, 90, 120, 150 and 180 days post-infection, the number of acid fast bacilli (AFB) per foot pad was determined. Each symbol represents one mouse. The threshold of counting ability is $4.8 \times 10^{3}$ AFB per foot pad; B: RNA was purified from foot pad tissue from mice in (A) and subjected to real-time polymerase chain reaction for cytokines. Gene expression is normalized using GAPDH

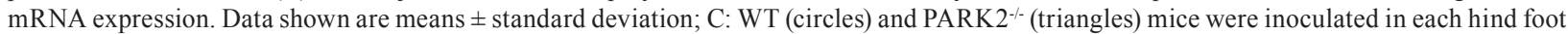
pad with $3 \times 10^{7}$ viable M. leprae. Foot pad induration was measured using a Vernier caliper. Data shown is mean \pm standard deviation of four mice per group; IFN: interferon; TNF: tumour necrosis factor; *: $\mathrm{p}<0.05 ; * *$ : $<0.01 ; * * * \mathrm{p}<0.001 ; * * *$ : $\mathrm{p}<0.0001$. 
TABLE II

Ridley-Jopling classification of armadillos from enzootic and non-enzootic areas using lepromin-A

\begin{tabular}{|c|c|c|c|c|c|}
\hline $\begin{array}{l}\text { Classification } \\
\text { Type (state) }\end{array}$ & $\begin{array}{c}\text { BL } \\
\mathrm{n}(\%)\end{array}$ & $\begin{array}{c}\text { BT } \\
\mathrm{n}(\%)\end{array}$ & $\begin{array}{c}\mathrm{LL} \\
\mathrm{n}(\%)\end{array}$ & $\begin{array}{c}\text { TT } \\
\mathrm{n}(\%)\end{array}$ & $\begin{array}{l}\text { Total } \\
\mathrm{n}(\%)\end{array}$ \\
\hline Enzootic (Louisiana) & $34(12.5)$ & $34(12.5)$ & $194(71.3)$ & $10(3.7)$ & $272(69.4)$ \\
\hline Non-enzootic (Florida, Mississippi, Texas) & $9(7.5)$ & $13(10.8)$ & $87(72.5)$ & $11(9.1)$ & $120(30.6)$ \\
\hline Total & $43(10.9)$ & $47(12)$ & $281(71.6)$ & $21(5.3)$ & $392(100)$ \\
\hline
\end{tabular}

chi-squared analysis show confirms that reactivity to lepromin varies among armadillos, but is not significantly different statistically $(\mathrm{p}=0.13)$ between animals from different parts of the United States of America range. BL: borderline lepromatous; BT: borderline tuberculoid; LL: lepromatous leprosy; TT: tuberculoid tuberculoid.

Hawn 2007). Polymorphisms on TLR 1 at $1805 \mathrm{GG}$ and 743 GG have been associated with impaired NFK-B signalling and various immunological responses to $M$. leprae affecting overall susceptibility to leprosy and the onset of reactional episodes, especially type 1 reactions (Johnson et al. 2007, Schuring et al. 2009). TLR2 polymorphisms also have been implicated in the immunological response to M. leprae. A SNP at locus C597T was particularly associated with reversal reactions in leprosy (Bochud et al. 2008) and another at C2029T was found to abrogate the ability of TLR-2 to mediate a response to M. leprae stimulation (Bochud et al. 2003). An additional polymorphism on TLR4 (896GG) also has been significantly linked to leprosy susceptibility (Bochud et al. 2009).

To explore the relationship TLR polymorphisms might have with the armadillo's response to M. leprae, we surveyed animals that had been routinely inoculated for in vivo propagation. We examined for various SNP loci and compared the frequency of each genotype among animals that had developed a disseminated infection within the usual two year time frame or which had completely resisted M. leprae for at least three years and never developed a detectable phenolic glycopid-1. IgM antibody response. Animals with disseminated infections were further subdivided as high or low responders depending on their yield of bacilli from reticuloendothelial system tissues at harvest $\left(<10^{7} \mathrm{bacilli} / \mathrm{gm}=\right.$ low responders and $>10^{11} \mathrm{bacilli} / \mathrm{gm}=$ high responders) $($ Table IV).

Using human TLR sequences as a template, we obtained the sequences of armadillo TLR genes from trace files at National Center for Biotechnology Information with the Dasypus archive. The armadillo consensus sequences retrieved were translated in-silico to the protein sequence and compared to the human TLR proteins. Armadillo TLR-1 showed 80\% (627/784) identity and $89 \%(699 / 784)$ positive amino acid homology. Available sequence identity for armadillo TLR2 and TLR4 compared to the human genes were $86 \%$ and $83 \%$ respectively. With primers designed to amplify regions flanking loci where SNP had been identified on human TLR, we inspected the sequences amplified from armadillos for polymorphisms. This technique could only detect homozygous polymorphisms.
TABLE III

Similarity of harvest results among sets of sibling armadillos experimentally infected with Mycobacterium leprae

\begin{tabular}{|c|c|c|c|c|}
\hline \multirow{2}{*}{$\begin{array}{l}\text { Sibling } \\
\text { set }\end{array}$} & \multirow[b]{2}{*}{ Animal } & \multicolumn{3}{|c|}{ Harvest bacillary count per gram liver } \\
\hline & & High & Low & Removed \\
\hline A & 9D24 & - & $1 \times 10^{7}$ & - \\
\hline A & 9D25 & - & $2.4 \times 10^{5}$ & - \\
\hline A & 9D27 & - & $1.1 \times 10^{8}$ & - \\
\hline B & 9D37 & - & - & Culled \\
\hline B & 9D38 & - & - & Culled \\
\hline B & 9D39 & - & - & Culled \\
\hline $\mathrm{C}$ & 9D43 & $1.1 \times 10^{9}$ & - & - \\
\hline $\mathrm{C}$ & 9D44 & $1.0 \times 10^{9}$ & - & - \\
\hline $\mathrm{D}$ & 9D46 & - & - & Culled \\
\hline $\mathrm{D}$ & 9D47 & - & - & Culled \\
\hline $\mathrm{E}$ & 9D53 & - & - & Culled \\
\hline $\mathrm{E}$ & 9D54 & - & $1.4 \times 10^{6}$ & - \\
\hline $\mathrm{E}$ & 9D56 & - & $2.4 \times 10^{8}$ & - \\
\hline $\mathrm{E}$ & 9D57 & - & - & Culled \\
\hline $\mathrm{F}$ & 8D93 & - & - & Culled \\
\hline F & 8D94 & - & $3.6 \times 10^{6}$ & - \\
\hline $\mathrm{F}$ & 8D95 & - & - & Culled \\
\hline G & $16 \mathrm{~F}$ & $5.3 \times 10^{9}$ & - & - \\
\hline G & $16 \mathrm{~F} 1$ & $1.7 \times 10^{10}$ & - & - \\
\hline G & $16 \mathrm{~F} 2$ & $7.8 \times 10^{9}$ & - & - \\
\hline $\mathrm{H}$ & 19F1 & $7.9 \times 10^{9}$ & - & - \\
\hline $\mathrm{H}$ & $19 \mathrm{~F} 2$ & - & $3.9 \times 10^{7}$ & - \\
\hline
\end{tabular}

among seven/eight of the sibling sets experimentally infected, each animal in the litter tended to respond similarly. Generally, litters were either high responders producing greater than $1 \times 10^{9} \mathrm{M}$. leprae/gram of liver or they yielded a non-productive infection with either low bacillary counts $\left(<1 \times 10^{9} \mathrm{M}\right.$. leprae/gram) or failed to thrive physically and required their early removal from production. Siblings were inoculated without lepromin screening.

We were unable to identify any polymorphism on armadillo TLR4 similarly positioned to G896A (D299G) as had been described human studies (Bochud et al. 2009) and we also found no polymorphisms on TLR2 corresponding to the general region of C2029 (Kang \& 
TABLE IV

Single nucleotide polymorphisms (SNP) in Toll-like receptors (TLR)

\begin{tabular}{|c|c|c|c|c|c|c|c|c|c|c|c|}
\hline \multirow{2}{*}{$\begin{array}{l}\text { Host/receptor } \\
\text { Human }\end{array}$} & & \multicolumn{4}{|c|}{ TLR1 } & \multicolumn{4}{|c|}{ TLR2 } & \multirow{2}{*}{\multicolumn{2}{|c|}{$\begin{array}{c}\text { TLR4 } \\
\text { A896G }\end{array}$}} \\
\hline & & \multicolumn{2}{|c|}{ A743G } & \multicolumn{2}{|c|}{$\mathrm{T} 1805 \mathrm{G}$} & \multicolumn{2}{|c|}{ C597- } & \multicolumn{2}{|c|}{ C2029T } & & \\
\hline Armadillo & & A7 & & A18 & & & & Not & & \multicolumn{2}{|c|}{ Not found } \\
\hline SNP & & $\mathrm{AA} / \mathrm{AG}$ & GG & $\mathrm{AA} / \mathrm{AG}$ & GG & $\mathrm{C}^{a} / \mathrm{CC}$ & $\mathrm{TT}$ & $\mathrm{CC} / \mathrm{CT}$ & $\mathrm{TT}$ & $\mathrm{GG} / \mathrm{AG}$ & AA \\
\hline \multirow[t]{2}{*}{ Disseminated } & high & 26 & 5 & 31 & 0 & 13 & 0 & 13 & 0 & 13 & 0 \\
\hline & low & 19 & 2 & 21 & 0 & 21 & 1 & 13 & 0 & 13 & 0 \\
\hline Resistant & & 8 & 2 & 6 & 4 & 8 & 2 & 10 & 0 & 10 & 0 \\
\hline
\end{tabular}

$a$ : deletion.

Chae 2001). However, we did find a polymorphism on armadillo TLR2 (C570T) located at a slightly different position than one previously reported on human TLR2 (C597T) (Bochud et al. 2008). With our small sample size the frequency was not significantly different statistically between groups. However, this mutation was present in two/10 armadillos that had completely resisted experimental infection compared to only one/34 that developed disseminated disease after experimental inoculation with $M$. leprae.

We also found two SNPs on armadillo TLR1 that were in slightly different positions than had been described in human studies (Johnson et al. 2007, Schuring et al. 2009). Armadillo TLR1 SNPs (A750G and A1879G) were found in the same general region of (A743G and $\mathrm{T} 1805 \mathrm{G}$ ) identified in the human gene sequence (Misch et al. 2008). The SNP, A750G was a synonymous polymorphism found in about $14 \%$ of the animals and its frequency did not differ significantly between the groups screened (Table IV). However, A1879G was non-synonymous polymorphism resulting in an amino acid change Arg 627 Gly and was found in about 6\% of all the animals screened (Table IV). This SNP was absent among animals that developed a disseminated disease, but was found in four/10 animals that completely resisted experimental infection for more than three years and appeared to be significantly associated with resistance to $M$. leprae in the armadillo (odds ratio 72.69 , confidence interval 95\% 3.498-1510, $\mathrm{p}=0.0004$ ). Additional studies will define the immunological response profile related to this genotype. However, this polymorphism may be an effective marker for resistance to $M$. leprae infection among armadillos and could prove to be a useful tool in selecting animals for experimental uses.

In review, animal models can play an important role in advancing our understanding of immunogenetic factors in leprosy through comparative studies helping to confirm the significance of various traits or polymorphisms observed in human studies and in deciphering the underlying mechanisms that may be involved in expression of different disease related phenotypes. Each model has distinctive benefits and uses. The mouse is ideal for studying the dynamic interplay of different aspects of the immune response to leprosy, especially in the formation and regulation of the granuloma. The ability to knockout specific pathways and investigate infection with a wide array of well defined immunological reagents and molecular probes is unparalleled. Though considerably more cumbersome, the armadillo is the only animal model with natural susceptibility to infection with $M$. leprae and they closely recapitulate many clinical aspects of leprosy seen in humans, especially extensive neurological involvement. With recent completion of their whole genomic sequence, armadillo specific reagents are no longer out of reach. An extensive battery of molecular reagents is already available and recombinant cytokines and anti-cytokine polyclonal and monoclonal antibodies are being generated (Adams et al. 2005, Pena et al. 2008). Thus, studying defined infections in mouse and armadillo models can provide insights into the host-pathogen interactions involved in this complex disease.

\section{REFERENCES}

Adams JE, Pena MT, Gillis TP, Williams DL, Adams LB, Truman RW 2005. Expression of nine-banded armadillo (Dasypus novemcinctus) interleukin-2 in E. coli. Cytokine 32: 219-225.

Adams LB, Job CK, Krahenbuhl JL 2000. Role of inducible nitric oxide synthase in resistance to Mycobacterium leprae in mice. Infect Immun 68: 5462-5465.

Adams LB, Mason CM, Kolls JK, Scollard D, Krahenbuhl JL, Nelson S 1995. Exacerbation of acute and chronic murine tuberculosis by administration of a tumor necrosis factor receptor-expressing adenovirus. J Infect Dis 171: 400-405.

Adams LB, Scollard DM, Ray NA, Cooper AM, Frank AA, Orme IM, Krahenbuhl JL 2002. The study of Mycobacterium leprae infection in interferon-gamma gene-disrupted mice as a model to explore the immunopathologic spectrum of leprosy. J Infect Dis 185 (Suppl. 1): S1-S8.

Akira S, Takeda K 2004. Toll-like receptor signalling. Nat Rev Immunol 4: 499-511.

Alcais A, Alter A, Antoni G, Orlova M, Nguyen VT, Singh M, Vanderborght PR, Katoch K, Mira MT, Vu HT, Ngyuen TH, Nguyen NB, Moraes M, Mehra N, Schurr E, Abel L 2007. Stepwise replication identifies a low-producing lymphotoxin-alpha allele as a major risk factor for early-onset leprosy. Nat Genet 39: 517-522.

Alter A, Grant A, Abel L, Alcais A, Schurr E 2011. Leprosy as a genetic disease. Mamm Genome 22: 19-31. 
Azouaou N, Gelber RH, Abel K, Sasaki DT, Murray LP, Locksley RM, Mohagheghpour N 1993. Reconstitution of Mycobacterium leprae immunity in severe combined immunodeficient mice using a T-cell line. Int J Lepr Other Mycobact Dis 61: 398-405.

Bean AG, Roach DR, Briscoe H, France MP, Korner H, Sedgwick JD, Britton WJ 1999. Structural deficiencies in granuloma formation in TNF gene-targeted mice underlie the heightened susceptibility to aerosol Mycobacterium tuberculosis infection, which is not compensated for by lymphotoxin. J Immunol 162: 3504-3511.

Berger AK, Cortese GP, Amodeo KD, Weihofen A, Letai A, LaVoie MJ 2009. Parkin selectively alters the intrinsic threshold for mitochondrial cytochrome c release. Hum Mol Genet 18: 4317-4328.

Berrington WR, Hawn TR 2007. Mycobacterium tuberculosis, macrophages and the innate immune response: does common variation matter? Immunol Rev 219: 167-186.

Bleharski JR, Li H, Meinken C, Graeber TG, Ochoa MT, Yamamura M, Burdick A, Sarno EN, Wagner M, Rollinghoff M, Rea TH, Colonna M, Stenger S, Bloom BR, Eisenberg D, Modlin RL 2003. Use of genetic profiling in leprosy to discriminate clinical forms of the disease. Science 301: 1527-1530.

Bochud PY, Hawn TR, Aderem A 2003. Cutting edge: a Toll-like receptor 2 polymorphism that is associated with lepromatous leprosy is unable to mediate mycobacterial signaling. $J$ Immunol 170: 3451-3454.

Bochud PY, Hawn TR, Siddiqui MR, Saunderson P, Britton S, Abraham I, Argaw AT, Janer M, Zhao LP, Kaplan G, Aderem A 2008. Toll-like receptor 2 (TLR2) polymorphisms are associated with reversal reaction in leprosy. J Infect Dis 197: 253-261.

Bochud PY, Sinsimer D, Aderem A, Siddiqui MR, Saunderson P, Britton S, Abraham I, Tadesse Argaw A, Janer M, Hawn TR, Kaplan G 2009. Polymorphisms in Toll-like receptor 4 (TLR4) are associated with protection against leprosy. Eur J Clin Microbiol Infect Dis 28: 1055-1065.

Boisson-Dupuis S, El Baghdadi J, Parvaneh N, Bousfiha A, Bustamante J, Feinberg J, Samarina A, Grant AV, Janniere L, El Hafidi N, Hassani A, Nolan D, Najib J, Camcioglu Y, Hatipoglu N, Aydogmus C, Tanir G, Aytekin C, Keser M, Somer A, Aksu G, Kutukculer N, Mansouri D, Mahdaviani A, Mamishi S, Alcais A, Abel L, Casanova JL 2011. IL-12Rbetal deficiency in two of fifty children with severe tuberculosis from Iran, Morocco and Turkey. PloS ONE 6: e18524.

Cardoso CC, Pereira AC, Brito-de-Souza VN, Duraes SM, RibeiroAlves M, Augusto CNJ, Francio AS, Vanderborght PR, Parelli FP, Alter A, Salgado JL, Sampaio EP, Santos AR, Leide Wr, Oliveira M, Sarno EN, Schurr E, Mira MT, Pacheco AG, Moraes MO 2011a. TNF-308G. A single nucleotide polymorphism is associated with leprosy among Brazilians: a genetic epidemiology assessment, meta-analysis, and functional study. J Infect Dis 204: 1256-1263.

Cardoso CC, Pereira AC, de Sales Marques C, Moraes MO 2011b. Leprosy susceptibility: genetic variations regulate innate and adaptive immunity and disease outcome. Future Microbiol 6: 533-549.

Chehl S, Ruby J, Job CK, Hastings RC 1983. The growth of Mycobacterium leprae in nude mice. Lepr Rev 54: 283-304.

Colston MJ, Hilson GR 1976. Growth of Mycobacterium leprae and M. marinum in congenitally athymic (nude) mice. Nature 262: 399-401.

Cooper AM, Adams LB, Dalton DK, Appelberg R, Ehlers S 2002a. IFN-gamma and NO in mycobacterial disease: new jobs for old hands. Trends Microbiol 10: 221-226.

Cooper AM, Kipnis A, Turner J, Magram J, Ferrante J, Orme IM 2002b. Mice lacking bioactive IL-12 can generate protective, an- tigen-specific cellular responses to mycobacterial infection only if the IL-12 p40 subunit is present. J Immunol 168: 1322-1327.

Cottle LE 2011. Mendelian susceptibility to mycobacterial disease. Clin Genet 79: 17-22.

Cruz A, Khader SA, Torrado E, Fraga A, Pearl JE, Pedrosa J, Cooper AM, Castro AG 2006. Cutting edge: IFN-gamma regulates the induction and expansion of IL-17-producing CD4 T cells during mycobacterial infection. J Immunol 177: 1416-1420.

Dawson PJ, Colston MJ, Fieldsteel AH 1983. Infection of the congenitally athymic rat with Mycobacterium leprae. Int $J$ Lepr Other Mycobact Dis 51: 336-346.

de Diego JL, Gerold G, Zychlinsky A 2007. Sensing, presenting and regulating PAMPs. Ernst Schering Found Symp Proc 3: 83-95.

Deretic V 2010. Autophagy in infection. Curr Opin Cell Biol 22: 252-262.

Ebenezer GJ, Arumugam S, Job CK 2002. Dosage and site of entry influence growth and dissemination of Mycobacterium leprae in T900r mice. Int J Lepr Other Mycobact Dis 70: 245-249.

Flynn JL, Goldstein MM, Chan J, Triebold KJ, Pfeffer K, Lowenstein CJ, Schreiber R, Mak TW, Bloom BR 1995. Tumor necrosis factor-alpha is required in the protective immune response against Mycobacterium tuberculosis in mice. Immun 2: 561-572.

Fukutomi Y, Matsuoka M, Minagawa F, Toratani S, McCormick G, Krahenbuhl J 2004. IL-10 treatment of macrophages bolsters intracellular survival of Mycobacterium leprae. Int J Lepr Other Mycobact Dis 72: 16-26.

Gros P, Skamene E, Forget A 1981. Genetic control of natural resistance to Mycobacterium bovis (BCG) in mice. J Immunol 127: 2417-2421.

Hagge DA, Marks VT, Ray NA, Dietrich MA, Kearney MT, Scollard DM, Krahenbuhl JL, Adams LB 2007. Emergence of an effective adaptive cell mediated immune response to Mycobacterium leprae is not impaired in reactive oxygen intermediate-deficient mice. FEMS Immunol Med Microbiol 51: 92-101.

Hagge DA, Ray NA, Krahenbuhl JL, Adams LB 2004. An in vitro model for the lepromatous leprosy granuloma: fate of Mycobacterium leprae from target macrophages after interaction with normal and activated effector macrophages. J Immunol 172: 7771-7779.

Hagge DA, Saunders BM, Ebenezer GJ, Ray NA, Marks VT, Britton WJ, Krahenbuhl JL, Adams LB 2009. Lymphotoxin-alpha and TNF have essential but independent roles in the evolution of the granulomatous response in experimental leprosy. Am J Pathol 174: 1379-1389.

Heldwein KA, Fenton MJ 2002. The role of Toll-like receptors in immunity against mycobacterial infection. Microbes Infect 4: 937-944.

Iwasaki A, Medzhitov R 2004. Toll-like receptor control of the adaptive immune responses. Nat Immunol 5: 987-995.

Jacobs M, Brown N, Allie N, Gulert R, Ryffel B 2000. Increased resistance to mycobacterial infection in the absence of interleukin10. Immunology 100: 494-501.

Job CK, Drain V, Truman R, Deming AT, Sanchez RM, Hastings RC 1992. The pathogenesis of leprosy in the nine-banded armadillo and the significance of IgM antibodies to PGL-1. Indian J Lepr 64: 137-151.

Job CK, Drain V, Williams DL, Gillis TP, Truman RW, Sanchez RM, Deming AT, Hastings RC 1991. Comparison of polymerase chain reaction technique with other methods for detection of Mycobacterium leprae in tissues of wild nine-banded armadillos. Lepr Rev 62: 362-373. 
Job CK, Kirchheimer WF, Sanchez RM 1982. Tissue response to lepromin, an index of susceptibility of the armadillo to M. leprae infection - a preliminary report. Int J Lepr Other Mycobact Dis 50: $177-182$.

Job CK, Kirchheimer WF, Sanchez RM 1983. Variable lepromin response to Mycobacterium leprae in resistant armadillos. Int $J$ Lepr Other Mycobact Dis 51: 347-353.

Job CK, Sanchez RM, Hastings RC 1985a. Effect of repeated lepromin testing on experimental nine-banded armadillo leprosy. Indian J Lepr 57: 716-727.

Job CK, Sanchez RM, Hastings RC 1985b. Manifestations of experimental leprosy in the armadillo. Am J Trop Med Hyg 34: 151-161.

Job CK, Sanchez RM, McCormick GT, Hastings RC 1985c. First lesion in experimental armadillo leprosy. Indian J Lepr 57: 71-77.

Johnson CM, Lyle EA, Omueti KO, Stepensky VA, Yegin O, Alpsoy E, Hamann L, Schumann RR, Tapping RI 2007. Cutting edge: a common polymorphism impairs cell surface trafficking and functional responses of TLR1 but protects against leprosy. J Immunol 178: 7520-7524.

Kaneko H, Yamada H, Mizuno S, Udagawa T, Kazumi Y, Sekikawa K, Sugawara I 1999. Role of tumor necrosis factor-alpha in Mycobacterium-induced granuloma formation in tumor necrosis factor-alpha-deficient mice. Lab Invest 79: 379-386.

Kang TJ, Chae GT 2001. Detection of Toll-like receptor 2 (TLR2) mutation in the lepromatous leprosy patients. FEMS Immunol Med Microbiol 31: 53-58.

Khader SA, Gopal R 2010. IL-17 in protective immunity to intracellular pathogens. Virulence 1: 423-427.

Khader SA, Pearl JE, Sakamoto K, Gilmartin L, Bell GK, JelleyGibbs DM, Ghilardi N, deSauvage F, Cooper AM 2005. IL-23 compensates for the absence of IL-12p70 and is essential for the IL-17 response during tuberculosis but is dispensable for protection and antigen-specific IFN-gamma responses if IL-12p70 is available. J Immunol 175: 788-795.

Kirchheimer WF, Sanchez RM 1981. Intraspecies differences of resistance against leprosy in nine-banded armadillos. Lepr India 53: $525-530$.

Kratz A, Campos-Neto A, Hanson MS, Ruddle NH 1996. Chronic inflammation caused by lymphotoxin is lymphoid neogenesis. J Exp Med 183: 1461-1472.

Levy L, Ji B 2006. The mouse foot-pad technique for cultivation of Mycobacterium leprae. Lepr Rev 77: 5-24.

Lin PL, Myers A, Smith L, Bigbee C, Bigbee M, Fuhrman C, Grieser H, Chiosea I, Voitenek NN, Capuano SV, Klein E, Flynn JL 2010. Tumor necrosis factor neutralization results in disseminated disease in acute and latent Mycobacterium tuberculosis infection with normal granuloma structure in a cynomolgus macaque model. Arthritis Rheum 62: 340-350.

Mira MT, Alcais A, Nguyen VT, Moraes MO, Di Flumeri C, Vu HT, Mai CP, Nguyen TH, Nguyen NB, Pham XK, Sarno EN, Alter A, Montpetit A, Moraes ME, Moraes JR, Dore C, Gallant CJ, Lepage P, Verner A, Van De Vosse E, Hudson TJ, Abel L, Schurr E 2004. Susceptibility to leprosy is associated with PARK2 and PACRG. Nature 427: 636-640.

Misch EA, Berrington WR, Vary JC Jr, Hawn TR 2010. Leprosy and the human genome. Microbiol Mol Biol Rev 74: 589-620.

Misch EA, Macdonald M, Ranjit C, Sapkota BR, Wells RD, Siddiqui MR, Kaplan G, Hawn TR 2008. Human TLR1 deficiency is associated with impaired mycobacterial signaling and protection from leprosy reversal reaction. PLoS Negl Trop Dis 2: e231.
Moura DF, Teles RM, Ribeiro-Carvalho MM, Teles RB, Santos IM, Ferreira H, Fulco TO, Nery JA, Sampaio EP, Sarno EN 2007. Long-term culture of multibacillary leprosy macrophages isolated from skin lesions: a new model to study Mycobacterium leprae-human cell interaction. Br J Dermatol 157: 273-283.

Pattyn SR 1965. Comparative behaviour of a strain of M. leprae in 5 different mouse strains and in thymectomized mice. Zentralbl Bakteriol, Parasit, Infektionskr Hyg 197: 256-258.

Pena MT, Adams JE, Adams LB, Gillis TP, Williams DL, Spencer JS, Krahenbuhl JL, Truman RW 2008. Expression and characterization of recombinant interferon gamma (IFN-gamma) from the ninebanded armadillo (Dasypus novemcinctus) and its effect on Mycobacterium leprae-infected macrophages. Cytokine 43: 124-131.

Rees RJ 1966. Enhanced susceptibility of thymectomized and irradiated mice to infection with Mycobacterium leprae. Nature 211: 657-658.

Reisner FKD 1943. Twin studies on the significance of genetic factors in tuberculosis. Am Rev Tuberculosis 47: 549-574.

Rennert PD, Browning JL, Mebius R, Mackay F, Hochman PS 1996. Surface lymphotoxin alpha/beta complex is required for the development of peripheral lymphoid organs. J Exp Med 184: 1999-2006.

Roach DR, Briscoe H, Saunders B, France MP, Riminton S, Britton WJ 2001. Secreted lymphotoxin-alpha is essential for the control of an intracellular bacterial infection. J Exp Med 193: 239-246.

Schuring RP, Hamann L, Faber WR, Pahan D, Richardus JH, Schumann RR, Oskam L 2009. Polymorphism N248S in the human Toll-like receptor 1 gene is related to leprosy and leprosy reactions. J Infect Dis 199: 1816-1819.

Schurr E, Buschman E, Malo D, Gros P, Skamene E 1990. Immunogenetics of mycobacterial infections: mouse-human homologies. J Infect Dis 161: 634-639.

Scollard DM, Adams LB, Gillis TP, Krahenbuhl JL, Truman RW, Williams DL 2006a. The continuing challenges of leprosy. Clin Microbiol Rev 19: 338-381.

Scollard DM, Joyce MP, Gillis TP 2006b. Development of leprosy and type 1 leprosy reactions after treatment with infliximab: a report of 2 cases. Clin Infect Dis 43: e19-22.

Scollard DM, Lathrop GW, Truman RW 1996. Infection of distal peripheral nerves by $M$. leprae in infected armadillos: an experimental model of nerve involvement in leprosy. Int J Lepr Other Mycobact Dis 64: 146-151.

Scollard DM, Truman RW 1999. The armadillo leprosy model with particular reference to lepromatous neuritis. In Handbook of Animal models of infection, Academic Press, New York, p. 331-335.

Shepard CC 1960. The experimental disease that follows the injection of human leprosy bacilli into foot-pads of mice. J Exp Med 112: $445-454$.

Shepard CC 1962. Multiplication of Mycobacterium leprae in the foot-pad of the mouse. Int J Lepr 30: 291-306.

Soroosh P, Doherty TA, So T, Mehta AK, Khorram N, Norris PS, Scheu S, Pfeffer K, Ware C, Croft M 2011. Herpesvirus entry mediator (TNFRSF14) regulates the persistence of T helper memory cell populations. J Exp Med 208: 797-809.

Storrs EE, Williams RJ 1968. A study of monozygous quadruplet armadillos in relation to mammalian inheritance. Proc Natl Acad Sci USA 60: 910-914.

Taulman JF, Robbins LW 1996. Recent range expansion and distributional limits of the nine-banded armadillo (Dasypus novemcinc$t u s$ ) in the United States. J Biogeography 23: 635-648. 
Torrado E, Cooper AM 2010. IL-17 and Th17 cells in tuberculosis. Cytokine Growth Factor Rev 21: 455-462.

Truman RW, Krahenbuhl JL 2001. Viable M. leprae as a research reagent. Int J Lepr Other Mycobact Dis 69: 1-12.

Truman RW, Morales MJ, Shannon EJ, Hastings RC 1986. Evaluation of monitoring antibodies to PGL-1 in armadillos experimentally infected with M. leprae. Int J Lepr Other Mycobact Dis 54: 556-559.

Truman RW, Sanchez RM 1993. Armadillos: models for leprosy. Lab Animal 22: 28-32.

Truman RW, Singh P, Sharma R, Busso P, Rougemont J, Paniz-Mondolfi A, Kapopoulou A, Brisse S, Scollard DM, Gillis TP, Cole ST 2011. Probable zoonotic leprosy in the southern United States. N Engl J Med 364: 1626-1633. van de Vosse E, van Dissel JT, Ottenhoff TH 2009. Genetic deficiencies of innate immune signalling in human infectious disease. Lancet Infect Dis 9: 688-698.

Ware CF 2005. Network communications: lymphotoxins, LIGHT and TNF. Annu Rev Immunol 23: 787-819.

Yamamura M, Uyemura K, Deans RJ, Weinberg K, Rea TH, Bloom BR, Modlin RL 1991. Defining protective responses to pathogens: cytokine profiles in leprosy lesions. Science 254: 277-279.

Yogi Y, Nakamura K, Inoue T, Kawatsu K, Kashiwabara Y, Sakamoto Y, Izumi S, Saito M, Hioki K, Nomura T 1991. Susceptibility of severe combined immunodeficient (SCID) mice to Mycobacterium leprae: multiplication of the bacillus and dissemination of the infection at early stage. Nihon Rai Gakkai Zasshi 60: 139-145. 